\title{
Effect of vigabatrin (gamma-vinyl GABA) on amino acid levels in CSF of epileptic patients
}

\author{
A PITKÄNEN, R MATILAINEN,* T RUUTIAINEN,* M LEHTINEN, P RIEKKINEN \\ From the Department of Neurology, University of Kuopio and Vaajasalo Epilepsy Hospital, ${ }^{*}$ Kuopio, Finland
}

SUMMARY Vigabatrin ( $\gamma$-vinyl GABA) is a new anticonvulsive drug that irreversibly inhibits the activity of GABA transaminase. The effect of vigabatrin on neurotransmission-related amino acids in CSF of 28 epileptic patients was studied and the relationship between the amino acid pattern and clinical response during 7 months of administration of vigabatrin. Of this study population, $46 \%$ had more than $50 \%$ decrease in seizure frequency (responders). In 54\% the seizures decreased less than $50 \%$ (nonresponders). In the whole study group, the levels of total GABA during vigabatrin treatment were $283 \%$, free GABA $197 \%$, homocarnosine $310 \%$ and glycine $128 \%$ that of the levels at baseline in the same patients. Glutamate, glutamine, aspartate, asparagine, and taurine concentrations did not change. The amino acid pattern in CSF during administration of vigabatrin did not differ significantly in responders and nonresponders. The study suggests that both GABAergic and glycinergic neurotransmission are affected by vigabatrin. The changes in CSF levels of neurotransmitter amino acids are, however, not necessarily related to the clinical response.

Vigabatrin ( $\gamma$-vinyl GABA, 5-amino-4-hex-enoic acid), is an anticonvulsive drug that inhibits GABA transaminase (GABA-T, EC 2.6.1.19) activity by an irreversible mechanism.' Levels of GABA and homocarnosine (HC) in the brain and cerebrospinal fluid (CSF) of animals as well as CSF levels of GABA and $\mathrm{HC}$ in humans are elevated up to $2-4$ fold during vigabatrin administration at doses that have anticonvulsive efficacy. ${ }^{12}$

Previous data about the unchanged levels of markers of cholinergic, dopaminergic, serotonergic and peptidergic systems ${ }^{34}$ and the relatively few side effects observed in patients during vigabatrin administration suggest that the mechanism of action is quite specific. However, the elevation of GABA levels alone seems not to explain all the effects of vigabatrin. First, studies of the rat brain suggest that other amino acids, such as $\beta$-alanine and hypotaurine, are also affected by vigabatrin. ${ }^{5}$ Second, the maximal elevations of GABA levels in the brain and CSF are not always correlated with maximal anticonvulsive efficacy. ${ }^{6}$ Third, elevation of CSF levels of GABA seems to be a constant finding in patients receiving vigabatrin, but the anticonvulsive effect is found only in $40-60 \%$ of these

Address for reprint requests: Asla Pitkänen, MD, Department of Neurology, University of Kuopio, Canthia, PO Box 6, 70211 Kuopio, Finland.

Received 29 April 1988.

Accepted 13 June 1988 patients. ${ }^{78}$ Fourth, vigabatrin seems to suppress different types of seizures both in animals and humans, and previous studies have proposed different anatomical and biochemical backgrounds for different types of seizures. This suggests that other transmitter systems than GABA are also involved in seizure regulation..$^{-11}$ Finally, the metabolic connections between GABA and other amino acids (especially glutamate) suggest that chronic elevation of GABA in the brain could induce secondary changes in other amino acids.

In the present study we determine the levels of excitatory (glutamate (Glu), aspartate (Asp)) and inhibitory (GABA, taurine (Tau), glycine (Gly)) amino acids and three amino acids related to them metabolically (glutamine (Gln), asparagine (Asn), homocarnosine (HC)) in CSF of epileptic patients receiving different doses of vigabatrin. The overall effect of vigabatrin on the amino acid pattern was evaluated as well as the relationship between changes in amino acid levels and clinical response.

\section{Patients and methods}

\section{Patients}

Twenty eight patients with drug-refractory epilepsy were included in the study. Each patient had at least three seizures per month. The mean age of the patients (18 male, 10 female) was 29.6, (SD 8.5) years (range 16-44). The mean duration of epilepsy was 26.1, (SD 9-2) years (range 15-43). Twenty-four 
of the patients had partial type epilepsy and four had primary generalised tonic-clonic seizures (PG). The mean frequencies of seizures in these two groups were 17.5, (SD 14.2) (range 354) per month and $44 \cdot 1$, (SD 25.9) (range 6-62) per month, respectively. The diagnosis of epilepsy and classification of seizure types were based on clinical history, electroencephalogram (EEG), and computed tomography of the head (CT). The aetiology of seizures was infection (encephalitis, meningitis) in three cases, trauma in two, birth asphyxia in five, miscellaneous (tuberous sclerosis, prenatal complications) in three, and unknown in $\mathbf{1 5}$ of the patients.

Interictal EEG was abnormal in all patients. Interictal irritation was found in $23(82 \%)$ patients. Increased theta or delta activity was seen in all $28(100 \%)$ cases. CT was abnormal in $22(79 \%)$ of these patients. The patients were receiving different combinations of carbamazepine, clonazepam, valproate, phenytoin, phenobarbital and primidone. Seven $(25 \%)$ patients had only one drug (carbamazepine), eight ( $29 \%$ ) had two drugs, and $13(46 \%)$ had three. The daily dose of anticonvulsive medication was kept constant during vigabatrin administration. Eight patients had Lennox syndrome, and they were classified according to the main type of seizure.

The age- and sex-matched control patients $(8$ males, 4 females; mean age 30.3 (SD 8.8) years, range 20-48) were investigated in the neurological unit for headache or paraesthesia of the extremities with no neurological finding on clinical examination. EEG and CT were normal for all controls.

\begin{abstract}
Administration of vigabatrin
In this open study vigabatrin was added to the previous antiepileptic medication for 7 months. The study protocol consisted of a 3 month baseline phase during which the baseline mean frequency of seizures per month was recorded. Thereafter vigabatrin treatment was started, and during the next 3 months the dose was titrated monthly according to the response and the observed side effects (dose-modification phase). For the next 4 months (long-term therapy phase) the vigabatrin dose was kept constant. The criteria for continuing to the long-term therapy phase were: (1) number of seizures per month reduced by more than $50 \%$, with or without global improvement (GI) (responders, Group A), (2) number of seizures reduced by less than $50 \%$ with GI (Group B). Patients with less than $50 \%$ reduction in seizures without GI (Group C) were excluded from the study after the dosemodification phase. In further data analysis Groups B and C were called nonresponders.
\end{abstract}

\section{Collection of CSF}

After the Ethics Committee of Vaajasalo Epilepsy Hospital had given its approval and the patients had given their oral consent, lumbar samples of CSF were collected. Patients had been immobile and had fasted overnight (0800-1000 h) before the sample was taken. CSF samples were divided into aliquots immediately and frozen in liquid nitrogen. They were then stored at $-70^{\circ} \mathrm{C}$ until analysed. Amino acids were measured from the pool of CSF containing the 5-10th $\mathrm{ml}$ of CSF. Samples taken from the same patient before and during vigabatrin therapy were analysed at the same time. Only one sample was taken from each control. From the epileptic patients the first sample was collected before the administra- tion of vigabatrin. The second sample was taken after 7 months of therapy with vigabatrin or if vigabatrin had to be stopped due to a poor response after the dose-modification phase.

\section{Amino acid analysis}

The levels of Glu, Gln, Asp, Asn, total GABA (TGABA), free GABA (FGABA), homocarnosine (HC), Tau, Gly, and vigabatrin were analysed by high performance liquid chromatography as described previously. ${ }^{3}$

\section{Statistical analysis}

The statistical analyses were performed at Kuopio University Computer Center by SPSS-programs. The statistical significance of parameters from the same patients at different times (two time points) was evaluated by Wilcoxon's test for matched samples. Differences between the controls and patients with epilepsy or between other groups were evaluated by Mann-Whitney U-test. The correlation between the different parameters was evaluated by Spearman's correlation test.

\section{Results}

Of the study population, $13(46 \%)$ had more than $50 \%$ $(p<0.001)$ decrease in seizure frequency (responders). In $15(54 \%)$ of the patients the seizures decreased, but by less than $50 \%(\mathrm{p}<0.01)$ (nonresponders); and for five of this patient group vigabatrin was stopped after the 3 month dosemodification phase due to the poor anticonvulsive response (Group $\mathrm{C}$ ). Ten of the nonresponders showed global improvement during vigabatrin therapy (social activity, improved communication, daily activities) (Group B) and continued to the long-term phase. In this group a slight decrease in seizure-frequency was also observed (to $73 \%$, $\mathrm{p}<0.01$ ).

In the whole study group the seizure frequency decreased to $50.2 \%(\mathrm{p}<0.001)$ at the time of the second lumbar puncture, as compared with baseline (table 1). Especially were the partial types of seizures suppressed (to $46.9 \%, p<0.001$ ). The number of primary generalised seizures also decreased, but the difference was not significant (to $55 \%, n=4, p=$ 0.0679). The vigabatrin doses and levels in CSF are shown in table 2. Vigabatrin did not affect the plasma levels of other anticonvulsive medication.

In the whole patient group the administration of vigabatrin elevated (see fig) the CSF levels of TGABA by $283 \%$ ( $p<0.001$, range $170-470 \%$ ), FGABA by $197 \%(p<0.001$, range $117-386 \%)$, and $\mathrm{HC}$ by $310 \%$ (p < 0.001, range 199-586\%) compared with the levels at baseline in all patients. The mean elevation of Gly was $128 \%(p<0.001$, range $84-175 \%$ ) of that at baseline. Glycine levels were elevated in all except two patients. Glu, Gln, Asp, Asn, and Tau levels were unchanged during vigabatrin administration. The 
Table 1 Effect of vigabatrin on frequency of seizures in different groups of patients

\begin{tabular}{|c|c|c|c|}
\hline \multirow[b]{2}{*}{ Group of patients } & \multicolumn{2}{|c|}{ Seizure frequency per month } & \multirow[b]{2}{*}{ Significance } \\
\hline & Baseline & During vigabatrin & \\
\hline $\begin{array}{l}\text { All } \\
\text { Responders } \\
\text { Nonresponders } \\
\text { Partial epilepsy } \\
\text { Primary generalised }\end{array}$ & $\begin{array}{l}21 \cdot 3 \text { (SD 18.3) (28) } \\
22.9 \text { (SD 18.2) (13) } \\
19.9 \text { (SD 18.9) (15) } \\
17 \cdot 5 \text { (SD 14.2) (24) } \\
44.1 \text { (SD 25.9) }(4)\end{array}$ & $\begin{array}{r}10 \cdot 7 \text { (SD 12.0) (26) } \\
6.5 \text { (SD 6.3) (13) } \\
14.9 \text { (SD 14.8) (13) } \\
8.2 \text { (SD 6.6) (22) } \\
24.3 \text { (SD 24.5)( } 4)\end{array}$ & $\begin{array}{l}p<0.001 \\
p<0.01 \\
p<0.01 \\
p<0.001 \\
\text { NS }\end{array}$ \\
\hline
\end{tabular}

Abbreviations: NS (nonsignificant). Values are expressed as a mean, (SD). Number of patients is in parenthesis. Statistical significance was evaluated by Wilcoxon test.

vigabatrin dose $(\mathrm{mg} / \mathrm{kg} /$ day $)$ correlated slightly with FGABA $(r=0.4037, \mathrm{n}=21, \mathrm{p}<0.05)$ and Asn $(r=$ $0.5537, \mathrm{n}=21, \mathrm{p}<0.01)$. The CSF levels of vigabatrin correlated with Asn $(r=0.6145, \mathrm{n}=21, \mathrm{p}$ $<0.01)$ and Gly $(\mathrm{r}=0.6554, \mathrm{n}=21, \mathrm{p}<0.01)$. No other correlations were found between the vigabatrin doses and levels of amino acids. When the amino acid patterns of epileptic patients and controls were compared, levels of $\mathrm{HC}$ and Gln were elevated and levels of Asp were lowered in CSF of epileptic patients. During vigabatrin therapy these differences were the same (fig).

The elevations in TGABA $(266 \%$ for responders and $298 \%$ for nonresponders of the levels at baseline), FGABA $(233 \%$ and $180 \%$ respectively), HC $(309 \%$ and $301 \%$, respectively), and Gly $(122 \%$ and $110 \%$, respectively) were observed in both responders and nonresponders (table 3). At baseline the nonresponders had slightly lower levels of TGABA and HC than the responders did. During vigabatrin therapy the Tau levels were lower $(69 \%)$ in nonresponders than in responders. In the nonresponders Tau levels were also lower than in controls both before and during vigabatrin administration. Gly levels were also slightly lower $(76 \%)$ in nonresponders than in responders during vigabatrin therapy. Their baseline levels of Gly were also lower $(88 \%)$ than in the controls. The FR \% (seizure frequency during vigabatrin administration per seizure frequency at baseline) correlated with Tau $(\mathrm{r}=-0.6379, \mathrm{n}=21, \mathrm{p}<0.05)$ levels in samples taken during vigabatrin treatment.

The CSF levels of vigabatrin and amino acids were about the same whether taken after 3 months or 7 months of vigabatrin administration. No difference in amino acid levels of CSF was observed between patients with partial type epilepsy and those with primary generalised seizures at baseline or during vigabatrin therapy.

The doses of vigabatrin (expressed either $\mathrm{g} /$ day or $\mathrm{mg} / \mathrm{kg} /$ day) and the CSF levels of vigabatrin did not differ between responders and nonresponders. Vigabatrin dose $(\mathrm{mg} / \mathrm{kg} /$ day $)$ correlated slightly with the CSF levels of vigabatrin $(r=0.5909, n=21, p<$ 0.01 ).

\section{Discussion}

The present study shows that administration of vigabatrin to epileptic patients affects GABAergic neurotransmission especially, but levels of glycine in CSF are also elevated. Furthermore, patients with good clinical response to vigabatrin had, for the most part, a pattern of amino acids in CSF similar to that in patients with poor response.

Most of the patients in the study had drugrefractory seizures of partial onset. Previous neuropathological, ${ }^{13}$ neurophysiological, ${ }^{14}$ and neuroradiological ${ }^{13}$ studies suggest that in such patients the limbic areas are affected most. Lloyd, et $a^{15}$ reported that $50-60 \%$ of the drug-refractory patients with partial epilepsy who were treated surgically had defects in GABAergic transmission. Such findings have not been confirmed in all studies. ${ }^{1617}$ Nor in the present study did we observe lowered GABA levels in CSF of epileptic patients. In the same group of patients, however, administration of vigabatrin resulted in a more than $50 \%$ decrease in seizure number in $47 \%$ of the patients with partial epilepsy and a concomitant $2 \cdot 5$-fold elevation of CSF levels of TGABA, which also reflects the elevation of brain GABA levels. ${ }^{18}{ }^{19}$ In the rest of the patients with partial epilepsy, however, the CSF levels of GABAergic

Table 2 Daily doses and CSF levels of vigabatrin in different groups of patients

\begin{tabular}{|c|c|c|c|}
\hline Group of patients & Vigabatrin (g/day) & Vigabatrin (mg/kg/day) & Vigabatrin in $C S F(\mu M)$ \\
\hline $\begin{array}{l}\text { All } \\
\text { Responders } \\
\text { Nonresponders }\end{array}$ & $\begin{array}{l}2.68 \text { (SD 0.50) (25) } \\
2.58 \text { (SD 0.40) (13) } \\
2.79 \text { (SD 0.58) (12) }\end{array}$ & $\begin{array}{l}44.12 \text { (SD 10.94) (25) } \\
46.31 \text { (SD 12.61) (13) } \\
41.75 \text { (SD 8.72) (12) }\end{array}$ & $\begin{array}{l}2.78 \text { (SD 1.06) (21) } \\
3.18 \text { (SD 1.04)(11) } \\
2.34 \text { (SD 0.94)(10) }\end{array}$ \\
\hline
\end{tabular}

Number of patients is in parenthesis. The vigabatrin values did not differ between groups (Mann-Whitney U-test). 


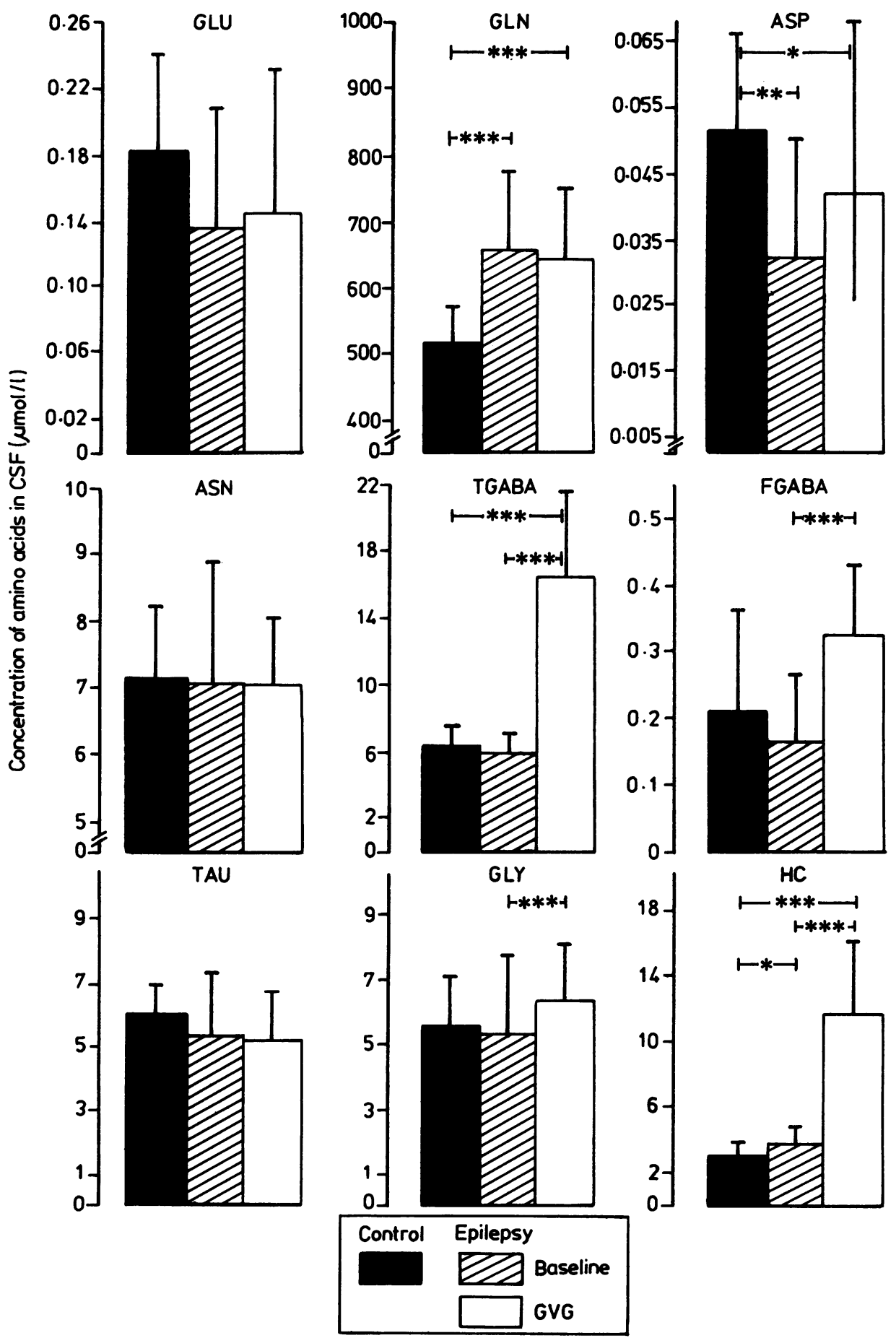

Fig Amino acid levels of epileptic patients before and during vigabatrin treatment, compared with controls. Values are expressed as mean, plus SD. Statistical significance: ${ }^{* *} p<0.001,{ }^{* *} p<0.01,{ }^{*} p<0.05$. 
Table 3 Amino acid levels in CSF of patients with different responses to vigabatrin

\begin{tabular}{|c|c|c|c|c|c|c|c|c|c|c|}
\hline \multicolumn{2}{|c|}{ Amino acid } & \multicolumn{2}{|c|}{ Controls $(\mu M)$} & \multicolumn{4}{|c|}{ Responders ( $\mu M)$} & \multicolumn{3}{|c|}{ Nonresponders $(\mu M)$} \\
\hline Glu & $\begin{array}{l}\text { baseline } \\
\text { vigabatrin }\end{array}$ & $0 \cdot 183$ & (SD 0.057) & $(12)$ & $\begin{array}{l}0.122 \\
0.137\end{array}$ & $\begin{array}{l}\text { (SD 0.067) } \\
\text { (SD 0.072) }\end{array}$ & (13)\| & 0.148 & (SD 0.076) & $(15)$ \\
\hline$G \ln$ & $\begin{array}{l}\text { baseline } \\
\text { vigabatrin }\end{array}$ & $509 \cdot 5$ & (SD 63.8) & (12) & $\begin{array}{l}629 \cdot 0 \\
627.9\end{array}$ & $\begin{array}{l}\text { (SD 114.4) } \\
\text { (SD 86.2) }\end{array}$ & $\begin{array}{l}(13) \S \\
(11) \S\end{array}$ & $\begin{array}{l}682.3 \\
654 \cdot 4\end{array}$ & $\begin{array}{l}(S D 0.100) \\
(S D 118 \cdot 8) \\
(S D ~ 132.0)\end{array}$ & $\begin{array}{l}\text { (10) } \\
\text { (15)‡ } \\
(10) \&\end{array}$ \\
\hline$A s p$ & $\begin{array}{l}\text { baseline } \\
\text { vigabatrin }\end{array}$ & 0.0512 & $2(\mathrm{SD} 0.0146)$ & 6) (12) & $\begin{array}{l}0.0349 \\
0.0313\end{array}$ & $\begin{array}{l}\text { (SD 0.0206) } \\
\text { (SD 0.0162) }\end{array}$ & $\left\{\begin{array}{l}(13) \| \\
(11) \S\end{array}\right.$ & $\begin{array}{l}0.0302 \\
0.0543\end{array}$ & $\begin{array}{l}2 \text { (SD 0.0158) } \\
3 \text { (SD 0.0562) }\end{array}$ & $\left\{\begin{array}{l}(15) \pm \S \\
(10)\end{array}\right.$ \\
\hline Asn & $\begin{array}{l}\text { baseline } \\
\text { vigabatrin }\end{array}$ & $7 \cdot 152$ & (SD 1·123) & $(12)$ & $\begin{array}{l}6.798 \\
7.075\end{array}$ & $\begin{array}{l}\text { (SD 1.764) } \\
\text { (SD 0.996) }\end{array}$ & (13) & $\begin{array}{l}7.286 \\
6.871\end{array}$ & $\begin{array}{l}\text { (SD 1.930) } \\
\text { (SD 1.111) }\end{array}$ & (15) \\
\hline$T G A B A$ & $\begin{array}{l}\text { baseline } \\
\text { vigabatrin }\end{array}$ & $6 \cdot 200$ & (SD 1.344) & $(12)$ & $\begin{array}{r}6 \cdot 292 \\
16.785\end{array}$ & $\begin{array}{l}\text { (SD 1.229) } \\
\text { (SD 5.635) }\end{array}$ & $\begin{array}{l}(13) \\
(11)^{*} \ddagger\end{array}$ & $\begin{array}{r}5 \cdot 309 \\
15 \cdot 754\end{array}$ & $\begin{array}{l}\text { (SD 1.034) } \\
\text { (SD 5.103) }\end{array}$ & $\begin{array}{l}(15) t+ \\
(10)^{*} t\end{array}$ \\
\hline$T G A B A$ & $\begin{array}{l}\text { baseline } \\
\text { vigabatrin }\end{array}$ & 0.210 & (SD 0.156) & (11) & $\begin{array}{l}0.124 \\
0.289\end{array}$ & $\begin{array}{l}\text { (SD 0.102) } \\
\text { (SD 0.121) }\end{array}$ & $\begin{array}{l}(13)^{*} \\
(11)^{*}\end{array}$ & $\begin{array}{l}0.199 \\
0.359\end{array}$ & $\begin{array}{l}\text { (SD 0.085) } \\
\text { (SD 0.078) }\end{array}$ & $\begin{array}{l}(15) * \\
(10)^{*} \|\end{array}$ \\
\hline Tau & $\begin{array}{l}\text { baseline } \\
\text { vigabatrin }\end{array}$ & 6.021 & (SD 0.946) & $(12)$ & $\begin{array}{l}5.672 \\
6.051\end{array}$ & $\begin{array}{l}\text { (SD 1.416) } \\
\text { (SD 1.353) }\end{array}$ & $\begin{array}{l}\text { (13) } \\
\text { (11) }\end{array}$ & $\begin{array}{l}4.993 \\
4.203\end{array}$ & $\begin{array}{l}\text { (SD 2.339) } \\
\text { (SD 1.053) }\end{array}$ & $\begin{array}{l}(15) \| \\
(10)\}^{* * *}\end{array}$ \\
\hline Gly & $\begin{array}{l}\text { baseline } \\
\text { vigabatrin }\end{array}$ & $5 \cdot 579$ & (SD 1.461) & $(12)$ & $\begin{array}{l}5.800 \\
7.060\end{array}$ & $\begin{array}{l}\text { (SD 2.491) } \\
\text { (SD 1.717) }\end{array}$ & $\begin{array}{l}\text { (13) } \\
\text { (11)十川 }\end{array}$ & $\begin{array}{l}4.917 \\
5.395\end{array}$ & $\begin{array}{l}\text { (SD 2.192) } \\
\text { (SD 1.187) }\end{array}$ & $\begin{array}{l}(15) \| \\
(10)^{*++}\end{array}$ \\
\hline$H C$ & $\begin{array}{l}\text { baseline } \\
\text { vigabatrin }\end{array}$ & $2 \cdot 963$ & (SD 0.817) & $(12)$ & $\begin{array}{r}4 \cdot 176 \\
12 \cdot 906\end{array}$ & $\begin{array}{l}\text { (SD 1.050) } \\
\text { (SD 5.799) }\end{array}$ & $\begin{array}{l}(13) \| \\
(11)^{*} \ddagger\end{array}$ & $\begin{array}{r}3 \cdot 389 \\
10 \cdot 212\end{array}$ & $\begin{array}{l}\text { (SD 0.955) } \\
\text { (SD 1.680) }\end{array}$ & $\begin{array}{l}(15) \ddagger \\
(10)^{*}+\dagger\end{array}$ \\
\hline
\end{tabular}

Abbreviations: HC (homocarnosine). Values are expressed as mean (SD). Statistical significance: ${ }^{*} \mathrm{p}<0.01$, $\nmid \mathrm{p}<0.05$ (compared with baseline values of the same patients, Wilcoxon test); $\ddagger p<0.001, \S p<0.01, \| p<0.05$ (compared with controls, Mann-Whitney U-test); ${ }^{* *} p<0.01, \dagger \dagger p$ $<0.05$ (difference between responders and nonresponders, Mann-Whitney U-test).

markers were elevated as much as in the group of responders.

The patients with primary generalised seizures also had elevated levels of GABA markers in CSF without prominent attenuation of seizures. Similarly animal studies have shown that vigabatrin affects the different types of seizures unequally. The response is good in audiogenic and photosensitive seizures and in seizures induced by picrotoxin or bicuculline. ${ }^{20}$ Kindled seizures are also suppressed by vigabatrin..$^{21}$ On the other hand, pentylenetetrazol-seizures can even be worsened by pretreatment with vigabatrin..$^{22}$ Recent studies suggest that different brain structures and transmitter amino acids may play a critical role in the regulation of different seizure types in animals. ${ }^{1023}$ Gale, et $a l^{10}$ suggested that the synaptosomal pool of GABA in neurons of the substantia nigra pars reticulata is important for the depression of seizure progression in animals after vigabatrin administration. The most critical areas for the antiepileptic effect of vigabatrin may not overlap with the anatomical substrates of different types of seizures, which may partly explain why some patients respond to vigabatrin and others continue to have frequent seizures despite elevated levels of GABA. In conclusion, potentiation of GABAergic neurotransmission alone is not sufficient to prevent seizures; but other factors are involved in seizure control, at least in some patients.

Vigabatrin inhibits GABA-T in both cortical and subcortical structures as well as in neuronal and glial compartments. ${ }^{10}$ Chronic elevation of GABA in widespread structures of the brain seems to have relatively few side effects and little effect on the EEG, ${ }^{12}$ which suggests few interactions with other neurotransmitters or neuromodulators, as was reported previously. ${ }^{34}$
However, we observed that during vigabatrin administration the levels of Gly, which is an inhibitory transmitter, are elevated in CSF by about $20 \%$ in almost all patients. This disagrees with previous animal studies, where the brain levels of glycine remained unchanged. The spinal cord obviously contributes significantly more to the CSF levels of Gly than does the brain tissue, which may partly explain the differences in brain and CSF data. Glycine elevation was poorly correlated with the clinical response. In addition, both the mechanism of elevation and the role of glycine in the anticonvulsive action of vigabatrin are unknown.

The neuronal tracts containing Glu and Asp seem to modulate effectively both the spread and neuropathological consequences of seizures in animals. ${ }^{24}$ In human epileptic foci Glu and Asp levels have been reported to be lowered. On the other hand, the plasma levels of Glu in patients with spike-and-wave epilepsy are elevated. ${ }^{25}$ We found lowered levels of these excitatory transmitters in the CSF of epileptic patients. Neither vigabatrin nor chronically elevated levels of GABA in the brain seemed to affect these amino acids. The metabolites, Gln and Asn, as well as Tau were also unchanged during vigabatrin therapy, which agrees with previous animal data. ${ }^{26}$

Baseline levels of amino acids in CSF of epileptic patients did not reveal any defect in GABAergic transmission or enhancement of excitatory transmission in epileptic patients compared with controls, as far as the CSF levels of amino acids reflect their functional state in the brain. The clinical response to vigabatrin could not be predicted on the basis of baseline values of amino acids, because the amino acid pattern of responders and nonresponders differed only in cases of TGABA and $\mathrm{HC}$, which later during 
vigabatrin therapy were equally elevated in the two groups. This finding also suggests that the GABAergic system in general can respond as effectively in nonresponders as in responders. No conclusions about anatomical and subcellular differences in GABA elevation between the two groups can be made on the basis of CSF data.

The present study suggests only a weak dose-dependency between vigabatrin dose and elevation of vigabatrin or amino acid levels in CSF or clinical response. The small number of patients included in the study as well as the narrow dose-range may have affected the results. Such correlations have been reported previously by Ben-Menachem, et al. ${ }^{27}$

In conclusion, both GABAergic and glycinergic transmissions are affected during vigabatrin administration in humans. Evidently the CSF levels of neurotransmission-related amino acids evaluated before or during vigabatrin adminstration are not necessarily related to the clinical response of vigabatrin. The present findings show, however, that enhancement of inhibitory neurotransmission in the central nervous system by vigabatrin has anticonvulsive efficacy in nearly half of the epileptic patients who had previously been drug-refractory.

We thank Ms Sari Karhunen for skilful technical assistance, Ms Maija-Liisa Airaksinen for typing the manuscript and the Merrel Dow Institute (France) for providing the vigabatrin.

\section{References}

1 Jung MT, Lippert B, Metcalf BW, Schechter PJ. $\gamma$-vinyl GABA (4amino-hex-5-enoic acid), a new selective irreversible inhibitor of GABA-T: effects on brain GABA metabolism in mice. J Neurochem 1977;29:797-802.

2 Schechter PJ, Hanke NFJ, Grove J, Huebert N, Sjoersma A. Biochemical and clinical effects of $\gamma$-vinyl GABA in patients with epilepsy. Neurology 1984;34:182-6.

3 Pitkänen A, Halonen T, Ylinen A, Riekkinen PJ. Somatostatin, $\beta$ endorphin, and prolactin levels in human cerebrospinal fluid during the $\gamma$-vinyl GABA treatment of patients with complex partial epilepsy. Neuropeptides 1987;9:185-95.

4 Riekkinen PJ, Pitkänen A, Halonen T, Lehtinen M, Ylinen A, Sivenius J. Effect of gamma-vinyl GABA treatment on cholinergic and aminergic neurotransmission and on cyclic nucleotides in human complex partial epilepsy-a CSF study. Prog. NeuroPsychopharmacol Biol Psychiatry 1988;12:81-91.

5 Grove J, Palfreyman MG, Schechter PJ. Cerbrospinal fluid GABA as an index of brain GABA activity. Clin Neuropharmacol 1983;6:223-9.

6 Riekkinen P, Ylinen A, Halonen T, Sivenius J, Pitkänen A. Relationship of GABA levels in CSF to clinical improvement during gamma-vinyl GABA (GVG) treatment in complex partial epilepsy. Neuroscience 1987;22(sapd):S68.

7 Pedersen SA, Klosterkov P, Grow L, Dam M. Long-term study of gamma-vinyl GABA in the treatment of epilepsy. Acta Neurol Scand 1985;72:295-8.

8 Loiseau P, Hardenberg JP, Pestre M, Guyot M, Schechter PJ, Tell GP. Double-blind, placebo-controlled study of Vigabatrin (gamma-vinyl GABA) in drug-resistant epilepsy. Epilepsia 1986;27:115-20.

9 Piredda S, Gale K. A crucial epileptogenic site in the deep prepiriform cortex. Nature 1985;317:61-3.

10 Gale K. Role of substantia nigra in GABA-mediated anticonvulsant actions. Adv Neurol 1986;44:343-64.

11 Mirski MA, Ferrendelli JA. Anterior thalamic mediation of generalized pentylenetetrazol seizures. Brain Res 1986;399: 212-23.

12 Matilainen R, Pitkänen A, Ruutiainen T, Mervaala E, Sarlund H, Riekkinen P. Effect of Vigabatrin on epilepsy in mentally retarded patients: a 7-month follow-up study. Neurology 1988;38:743-7.

13 Engel J Jr, Brown WJ, Kuhl DE, Phelps ME, Mazziotta JC, Crandall PH. Pathological findings underlying focal temporal lobe hypometabolism in partial epilepsy. Ann Neurol 1982;12:518-28.

14 Theodore WH. Recent advances in the diagnosis and treatment of seizure disorders. Trends in Neuroscience 1985;8:144-7.

15 Lloyd KG, Bossi L, Morselli PL, Munari C, Rougier M, Loiseau H. Alterations of GABA-mediated synaptic transmission in human epilepsy. Adv Neurol 1986;44:1033-44.

16 Perry TL, Hansen S, Kennedy J, Wada JA, Thomplsen GB. Amino acids in human epileptogenic foci. Arch Neurol 1975;32:752-4.

17 Perry TL, Hansen S. Amino acid abnormalities in epielptogenic foci. Neurology 1981;31:872-6.

18 Böhlen P, Huot S, Palfreyman MG. The relationship between GABA concentrations in brain and cerebrospinal fluid. Brain Res 1979;167:297-305.

19 Grove J, Schechter PJ, Hanke NFJ, et al. Concentration gradients of free and total $\gamma$-aminobutyric acid and homocarnosine in human CSF: comparison of suboccipital and lumbar sampling. $J$ Neurochem 1982;39:1618-22.

20 Meldrum B, Horton R. Blockade of epileptic responses in the photosensitive baboon, Papio Papio, by two irreversible inhibitors of GABA-transaminase, $\gamma$-acetylenic GABA (4amino-hex-5-ynoic acid) and $\gamma$-vinyl GABA (4-amino-hex-5enoic acid). Psychopharmocology 1978;59:47-50.

21 Shin C, Rigsbee LC, McNamara JO. Anti-seizure and antiepileptogenic effect of $\gamma$-vinyl $\gamma$-aminobutyric acid in amygdaloid kindling. Brain Res 1986;398:370-4.

22 Myslobodsky MS, Ackerman RF, Engel J Jr. Effects of $\gamma$ acetylenic GABA and $\gamma$-vinyl GABA on metrazol-activated, and kindled seizures. Pharmacol Biochem Behav 1979;11:265-71.

23 Piredda S, Pavlick M, Gale $K$. Anticonvulsant effect of GABA elevation in the deep prepiriform cortex. Brain Res 1987;1:102-6.

24 Turski L, Cavalheiro EA, Turski WA, Meldrum BJ. Excitatory neurotransmission within substantia nigra pars reticulata regulates threshold for seizures produced by pilocarpine in rats: effects of intranigral 2-amino-7-phosphonoheptanoate and $\mathrm{N}$ methyl-O-aspartate. Neuroscience 1986;18:61-77.

25 Janjua NM, Metrakos JD, Van Gelder NM. Plasma amino acids in epilepsy. In: Anderson VE, Hauser WA, Penry JK, Sing CF, eds. Genetic Basis of Epilepsies. New York: Raven Press, 1982:181-95.

26 Perry TL, Kish SJ, Hansen S. $\gamma$-vinyl GABA: effects of chronic administration on the metabolism of GABA and other amino compounds in the rat brain. $J$ Neurochem 1979;32:1641-5.

27 Ben-Menachem E, Persson LI, Hamberger A, Schechter P, Haegele KD, Mumford JP. Changes in CSF parameters and seizure control with every-third-day, every-other-day, and daily dosing of $\gamma$-vinyl GABA. Epilepsia 1986;27:649. 